\title{
The Application of Morpheme Teaching Method in Korean Classroom Teaching
}

\author{
Yang Min \\ Xi'an International University, Shaanxi, China, 710077
}

Keywords: vocabulary of Chinese as a foreign language, Korean kanji, morpheme teaching, vocabulary teaching

Abstract: The purpose of teaching Chinese as a foreign language is to enable students to apply what they have learned, and the huge vocabulary often restricts the pace of Chinese learning. For Korean students, a large number of Chinese words in Korean language make them have an innate advantage in learning Chinese vocabulary. The first question that needs to be clarified in the use of Korean kanji words to learn Chinese vocabulary is which unit is the basic teaching unit of vocabulary. This paper advocates the morpheme-based vocabulary teaching method, and on the basis of the morpheme teaching method, the Chinese characters in Korean are briefly sorted and classified, and finally combined according to the characteristics of Korean kanji. The morpheme teaching method proposes a vocabulary teaching method based on morpheme splitting vocabulary and inversely pushing Chinese words according to semantics, thus expanding Chinese vocabulary. This article has a total of four parts to discuss this.

\section{Introduction}

Vocabulary teaching has always been the focus of teaching Chinese as a foreign language. It is also difficult. For students learning Chinese, the correct use of Chinese vocabulary and the vocabulary they master determine the depth of their Chinese learning and the Chinese level of students. The study of the second language is the process of transition from the mother tongue to the target language. Students in the Western cultural background, especially those whose native language is Indo-European, are often influenced by the concept of "word-based" in their mother tongue when learning Chinese vocabulary. Usually, the meaning of the word is generally grasped. Once the word is taken apart to become a single morpheme, it is not known. For example, students can understand the meaning of "milk" and understand the meaning of "bean", but if "soy milk" is given, students cannot derive their meaning from the above two learned words ${ }^{[1]}$.

\section{Overview of Chinese Characters in Korean}

\subsection{Cultural Origins of Korean Chinese Words}

China and the Korean Peninsula (North Korea and South Korea) have been linked by mountains and rivers since ancient times, and their culture is also in the same vein. According to research, the 
connection between the Korean Peninsula and China can be traced back to the spring and Autumn Period and the Warring States Period. The ancient Chinese Han culture has a strong position in the Chinese character culture circle, and spreads in the form of radiation with the constant exchanges between countries. As a link between language and culture, Chinese characters entered the Korean peninsula in the second and third centuries BC with the spread of culture. Mr. Wang Li (1980) pointed out: "Since the Qin and Han Dynasties, due to the advanced culture of the Han culture, it has gradually been introduced to foreign countries, especially Japan, North Korea and Vietnam. Japanese, Korean and Vietnamese have all accepted the great influence of Chinese. Absorbing a large number of words into Chinese becomes an integral part of their own vocabulary ${ }^{[2]}$."

\subsection{Causes and sources of Korean kanji}

\subsubsection{Basic Concepts and Definitions of Chinese Characters}

In the Korean "Mandarin Dictionary", Chinese characters are interpreted in such a way: words that can be written in Chinese characters. Here we can see how the Koreans themselves understand Chinese characters. There are two kinds of viewpoints for the interpretation of Chinese characters: Wu Enxi (2008) can explain the Korean Chinese characters in the article "Korean Words in Korean and Chinese Character Teaching for Korean Students". Korean characters are marked by Chinese vocabulary." Professor Chen Liu (2007) made another explanation for Chinese characters in his book "The Language of the East: The Study of Korean Kanji Words": "we are talking about here.' Chinese character words', as the name implies, refers to words that can be marked with Chinese characters ${ }^{[2]}$. Specifically, it is the introduction or use of Chinese characters from Chinese vocabulary, and the Chinese characters are used in the vocabulary system of the national vocabulary system. These words are mostly derived from Chinese". Wu Enxi's statement points out the form of Korean kanji words--using Korean pronunciation habits; Chen Liu's statement points out the meaning of Korean kanji---the introduction or use of Chinese characters from Chinese vocabulary and already Chinese characters are included in the vocabulary system of the nation.

\subsubsection{Classification of Chinese word sources}

Chinese characters derived from Japan are called and Chinese characters and most of them entered the Korean language after the Opium War. In the 19th century, the world order changed greatly. After the Meiji Restoration in Japan, the national strength was gradually strengthened. A large number of Western cultural achievements were translated into the East by the Japanese. They used rich Chinese character resources to create a large number of reflections in accordance with the Chinese words. Japanese kanji words of Western learning. At this time, China is also borrowing a large amount of vocabulary from Japanese in the context of "teaching the world to control the economy," such as "social", "democracy", "economic", "state", and "liberation" in modern Chinese. The words "human rights" and "personality" are all borrowed from Japanese. At this time, due to the rapid rise of Japan's national strength, the Korean peninsula became a fate of Japan's glory. After 1875, Japan forced the North Korean government to sign a series of unequal treaties, and at the same time promoted enslavement education, forcing students to learn Japanese, so A large number of Japanese vocabulary continue to enter the Korean language. Although these vocabularies are derived from Japanese and have been absorbed by Chinese and Korean, the Japanese use the Chinese characters as morphemes to create these vocabulary based on the lyrics of Chinese characters ${ }^{[1]}$. 


\section{A morphological vocabulary teaching strategy combining Korean kanji}

\subsection{Korean kanji and morpheme teaching}

The goal of teaching Chinese as a second language is to "master the basic knowledge of Chinese and the basic skills of listening, speaking, reading and writing, and cultivate the ability to use Chinese for communication. This is the most direct and fundamental teaching purpose, and reflects the fundamental task of language teaching." (Liu Xun, 2000) It can be seen that the Chinese vocabulary teaching for Korean students focuses on cultivating students' communicative competence and the ability to use Chinese vocabulary flexibly. As can be seen from the foregoing, there is a lot of connection between Chinese and Korean. The phenomenon of a large number of Chinese characters in Korean is a good proof. Chinese characters are also an innate advantage for Korean students to learn Chinese. From the perspective of teaching, Chinese characters are a point of convergence between Chinese vocabulary and the mother tongue of students.

Table 1 Typical Korean vocabulary translation comparison

\begin{tabular}{|c|c|c|c|}
\hline Korean & English & Korean & English \\
\hline 니트 、세타 & KNIT & 티、긴팔티 & T-SHIRT \\
\hline 잠바、패딩 & JUMPER & 남방、셔츠 & SHIRT \\
\hline 패딩점퍼 & JACKET & 상의 & BLOUSE \\
\hline 코트、외투 & COAT & 레깅스、원피스 & ONE-PIECE \\
\hline 자켓、가죽잠바 & COAT & 치마 & SKIRT \\
\hline 상의 & COAT & 바지 & PANTS \\
\hline 솜옷 & CARTERS & 청바지 & JEANS \\
\hline
\end{tabular}

For a long time, the Chinese vocabulary teaching for Korean students still takes the old path of Chinese integration. Even in the face of the special form of Chinese characters, the lag of many teaching methods makes Chinese characters not being able to be widely used in the vocabulary teaching of Korean and Chinese.

\subsection{Vocabulary Teaching Using Chinese Words and Words Separation}

\subsubsection{The morpheme split method requires several clear questions}

Let us look back at what is a Korean kanji. Korean kanji refers to words that can be marked with Chinese characters. Specifically, they are introduced or applied from Chinese vocabulary and have been integrated into their own vocabulary. Chinese characters in the system are marked with words. Most of these words are derived from Chinese." (Chen Liu, 2007) In terms of quantity, Chinese characters account for more than $60 \%$ of the total number of Korean vocabulary. It can be said that every Korean is familiar with it. The author believes that the morpheme-based teaching method provides a good method for finding the connection between them. We can use the split word as the morpheme to establish the correspondence between Korean characters and Chinese characters, so as to use Korean kanji words. Expand the Chinese vocabulary of students to achieve the purpose of vocabulary teaching ${ }^{[3]}$. 


\subsubsection{How to integrate morpheme teaching into teaching}

The purpose of teaching Chinese as a foreign language is to enable students to apply what they have learned, but the vast Chinese language vocabulary often discourages many international students. The huge vocabulary restricts the pace of Chinese learning. Chinese is completely strange to students with Western culture as the background. However, for Korean students who are in the Chinese cultural circle, Chinese has always been inextricably linked with their mother tongue. It is the most familiar. Stranger". Due to historical reasons, there are a large number of Chinese characters in Korean, which account for more than $60 \%$. This part of the vocabulary retains the word formation features of Chinese vocabulary and has many similarities with Chinese vocabulary. For Korean students, the large number of Chinese characters is the innate advantage of their Chinese vocabulary.

Table 2 Seven Architectures of Network Education Learning System

\begin{tabular}{|c|c|}
\hline Number/name & Function \\
\hline $\begin{array}{l}\text { TS130 - Student Education } \\
\text { Record (Trouse Sheet) }\end{array}$ & $\begin{array}{l}\text { Used to Transfer Student Data Between Educational } \\
\text { Institutions }\end{array}$ \\
\hline $\begin{array}{l}\text { TS131 - Student Education } \\
\text { Record (Transcript) }\end{array}$ & $\begin{array}{l}\text { Confirmation Provides intelligent automatic } \\
\text { confirmation when student records are received }\end{array}$ \\
\hline $\begin{array}{l}\text { TS146 - Student Education } \\
\text { Record (Troble Sheet) }\end{array}$ & $\begin{array}{l}\text { Allow Educational Institutions to Submit Automated } \\
\text { Student Record Requests }\end{array}$ \\
\hline $\begin{array}{l}\text { TS147 - Response to student } \\
\text { education record (transcript) }\end{array}$ & request Automated response to student record request \\
\hline $\begin{array}{l}\text { TS132 - Human Resource } \\
\text { Information }\end{array}$ & $\begin{array}{l}\text { Used to Transfer Personnel Record Data Between } \\
\text { Educational Agents }\end{array}$ \\
\hline $\begin{array}{l}\text { TS133 - Educational } \\
\text { institutions }\end{array}$ & $\begin{array}{l}\text { Used to transmit information about educational } \\
\text { institution characteristics between educational agents }\end{array}$ \\
\hline TS152 - Government Statistics & Used to send responses to government surveys. \\
\hline
\end{tabular}

The author believes that if students want to use Chinese vocabulary to learn Chinese vocabulary and expand their vocabulary, it is first necessary to clarify what is the basic unit of vocabulary teaching. Since Chinese vocabulary teaching started late, the teaching method has always been based on the Indo-European vocabulary teaching method, which is the "word-based" teaching method.

\section{Conclusions}

Chinese is completely strange to students with Western culture as the background. However, for Korean students who are in the Chinese cultural circle, Chinese has always been inextricably linked with their mother tongue. It is the most familiar. Stranger". Based on the previous studies, this thesis proposes the morpheme-based teaching as the core, based on the establishment of the core morpheme meaning, using the Chinese characters in Korean to activate the Chinese vocabulary teaching method. It aims to expand the Chinese vocabulary of Korean students. When there is a clear theory as a guide, new teaching methods are coming out. Combined with the morpheme teaching method, using the characteristics of Korean kanji words, this paper proposes morpheme 
splitting, and the use of Chinese characters to activate Chinese vocabulary teaching methods can significantly improve the quality of teaching.

\section{References}

[1] Woo, Shik H. A Study on application of the teaching methods in Korean education [J]. Institute of Education of Korean Language \& Literature, 2016, 35.

[2] Jambor Z P. Favourable Teaching Approaches in the South Korean Secondary Classroom. [J]. Online Submission, 2017:12.

[3] Kim, Eunjin. A Study of Flipped Classroom Model for Korean Language as a foreign language Teaching Method [J]. Journal of General Education, 2016, 3:131. 